\title{
Ehsan Ahmed, Guillaume Briçonnet, Marguerite de Navarre and the Evangelical critique of Reason
}

\section{Filippo Fassina}

\section{(2) OpenEdition}

\section{Journals}

\section{Edizione digitale}

URL: http://journals.openedition.org/studifrancesi/8206

DOI: $10.4000 /$ studifrancesi.8206

ISSN: 2421-5856

\section{Editore}

Rosenberg \& Sellier

\section{Edizione cartacea}

Data di pubblicazione: 1 mai 2009

Paginazione: 156

ISSN: 0039-2944

\section{Notizia bibliografica digitale}

Filippo Fassina, «Ehsan Ahmed, Guillaume Briçonnet, Marguerite de Navarre and the Evangelical critique of Reason», Studi Francesi [Online], 157 (LIII | I) | 2009, online dal 30 novembre 2015, consultato il 09 janvier 2021. URL: http://journals.openedition.org/studifrancesi/8206 ; DOI: https://doi.org/10.4000/ studifrancesi.8206

Questo documento è stato generato automaticamente il 9 janvier 2021.

\section{(c) $(1) \odot$}

Studi Francesi è distribuita con Licenza Creative Commons Attribuzione - Non commerciale - Non opere derivate 4.0 Internazionale. 


\title{
Ehsan Ahmed, Guillaume Briçonnet, Marguerite de Navarre and the Evangelical critique of Reason
}

\author{
Filippo Fassina
}

\section{NOTIZIA}

EHSAN AHMED, Guillaume Briçonnet, Marguerite de Navarre and the Evangelical critique of Reason, «Bibliothèque d'Humanisme et Renaissance», LXIX, 3 (2007), pp. 615-625.

L'A., partendo dalla fitta corrispondenza fra Guillaume Briçonnet e Marguerite de Navarre, analizza uno dei nodi principali della dottrina del vescovo evangelico, l'«evangelical critique of reason». In particolare, questo studio si sofferma su due questioni di capitale importanza: l'incompatibilità di spirito e ragione e l'impossibilità della conoscenza di Dio. Vengono poi brevemente analizzati i legami con le principali fonti di Briçonnet: lo Pseudo-Dionigi (edito nel 1499 da Lefèvre d'Étaples, collaboratore dello stesso Briçonnet) e Nicola Cusano, soprattutto per quanto riguarda l'inaccessibilità da parte della mente umana del mistero divino. 